\title{
MODELLING OF MSMA COMPONENTS: POROUS PAVEMENT WITH DETENTION SYSTEM UNDERNEATH FOR LOW TRAFFIC ROADS
}

\author{
Darrien Yau Seng Mah ${ }^{1}$, Boon Yee Koh ${ }^{2}$, Frederik Josep Putuhena ${ }^{3}$, Nor Azalina Bt Rosli ${ }^{4}$ \\ 1,2,3,4Faculty of Engineering, Universiti Malaysia Sarawak, 94300 Kota Samarahan, Sarawak
}

Date received: 7/2/2016, Date accepted: 13/4/2016

Corresponding author's email: ysmah@feng.unimas.my

\begin{abstract}
This study has been made in order to pursue practices in Water Sensitive Urban Design (WSUD), where stormwater management becomes a mainstream in Malaysia. The main focus of this study is to develop a stormwater conveyance model incorporating porous pavement and on-site detention system at Heights Drive (Stutong), Kuching City, and to investigate its effectiveness. Conventional pavements are impervious and create contaminated runoff. In contrast, combination of porous pavement with storage as WSUD approach allows stormwater to percolate to an underlying detention system where stormwater is both infiltrated to underlying clay soil and discharged with a lower rate to drain beside the road. Nine roads with total surface area of $12,660 \mathrm{~m}^{2}$ are selected and a total of 6 scenarios are modelled and simulated using EPA's SWMM 5.0. It is found that the peak discharge at outfall from the study area is decreased by $23 \%$, in which $2 \%$ of the stormwater is infiltrated to the ground for groundwater recharge.
\end{abstract}

Keywords: Control at source, runoff, subsurface storage, SWMM, water sensitive urban design

\subsection{INTRODUCTION}

$\mathrm{T}$

The impact of urbanization on the natural world has risen dramatically with decreases infiltration of storm water and increases runoff which against the balance of nature. The modern infrastructures such as roads, sidewalks, commercial and residential structures, cover the permeable terrain resulting in high surface runoff. The runoff then flows into urban storm water drainage. Disaster such as flash flood takes place when the urban storm water drainage design fails or frequent flows overwhelm the design capabilities. The surface runoff is directly discharged to rivers or streams via urban storm water drainage. Thus, harmful pollutants such as heavy metals, organic matter, oil and excess nutrients enter the storm water during the flowing processes from roof to sidewalk, to drains and to rivers.

As such, the pursuit of "sustainability" has emerged in recent years as a progression from previous "environmental protection" endeavours. Many communities have started incorporating Water Sensitive Urban Design (WSUD) practices into their water and storm water management plans and regulations [1]. Critical issues resulting from poor water management are concerned by federal regulations. For example, the Malaysian Department of Irrigation and Drainage has instituted Mannual Saliran Mesra Alam (MSMA) or Urban Stormwater Management Manual for Malaysia, since 2000. MSMA basically is a product driven by WSUD approach, addressing sustainability in storm water management. WSUD practices have been incorporated into many communities and projects, such as rain gardens, porous paving, green roofs, grey water and rain water re-use systems [2].

In this paper, the authors focus on porous pavement and underground detention storage. Conventional pavements are impervious and thus creating running water at ease. Contradictorily, porous pavement allows the stormwater to percolate under it and then infiltrate into the ground with time. Such pavement and associated detention system are normally represented in mathematics and thus can be modelled to provide insights of its limitations and effectiveness [3]-[4]. 
In urban areas, tar road surfaces collectively contribute to a major portion of impervious ground covers; thus it plays a major role in determining the quantity of surface runoff. Franklin Institute Research Laboratories in the United States was regarded as the pioneer for research into new pavement types in the late 1960s. One of the developed programs was the study on porous pavement, an endeavour supported by the United States Environmental Protection Agency (EPA). Since then, numerous models of porous pavement are available in the market. Generally, such pavement type is developed to reduce the runoff rates and growing volumes of storm water collected in urbanized areas. Figure 1 presents an example of a typical porous section for parking lots and light-weight vehicle pavements [5]-[6] that was provided by an EPA-sponsored project.

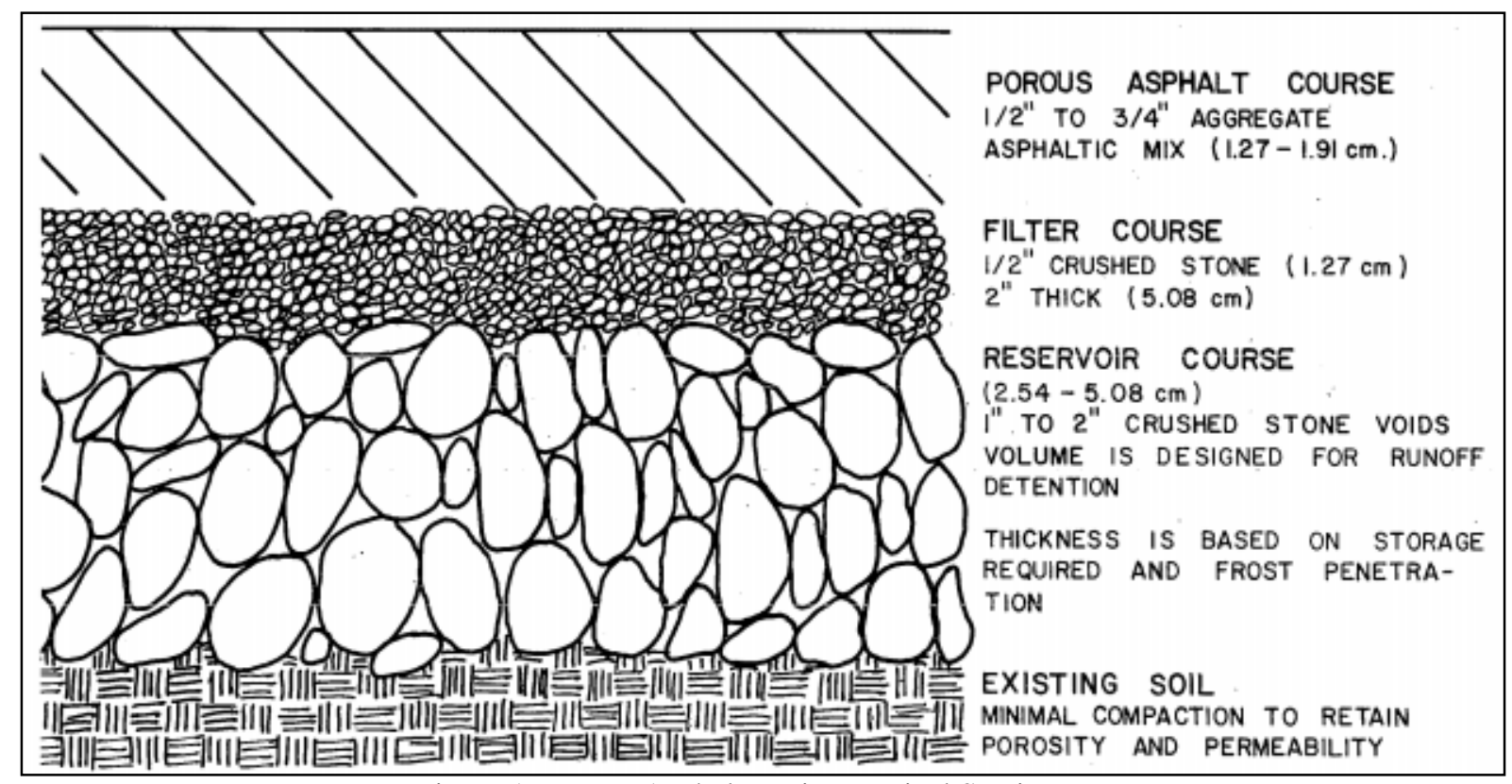

Figure 1. Porous Asphalt Paving Typical Section [7]

The porous layer, either asphalt or concrete, consists of small voids over the finished pavement. They should meet storm water demands while providing a hard surface, which can be utilized in urban areas [8]. Water is able to drain through quickly to the thick layer of gravel at the bottom layer of the pavement [9]. However, this base course can also be replaced by concrete blocks, which contain open cells; hence a subsurface detention system is created.

\subsection{SUBSURFACE DETENTION SYSTEM}

Subsurface detention system, in this case, is referring to a system connected to porous pavement described previously. The porosity of the pavement leads surface stormwater to subsurface chambers. Collected stormwater is stored temporarily within the chambers, and it is slowly released to nearby drains. This could be facilitated with a properly-sized outlet so that the outflow could be controlled near to predevelopment flow rate. With careful design, the retained water can also be directed to infiltrate to groundwater recharge while preventing running water to cause erosion problems on the ground surface. As such, they capture portions of surface runoff, attenuating them from washing downstream.

\subsection{PROPOSED MEASURE}

The study area is located at Heights Drive housing estate in the Suburb Stutong of Kuching City as shown in Figure 2. A housing estate is a suitable choice, for its traffic load is low (JKR U1 roads) and at 
a control low speed of maximum $40 \mathrm{~km} / \mathrm{hour}$. For existing housing estates, building and its attached land belongs to property owner but the road belongs to the government. Therefore, porous pavement with underground detention system is practicable. Retrofitting of such system is workable than having a detention system within private lands. The latter can only be implemented by encouraging land owners to adopt one, usually accompanied with subsidies or compensations from the government.

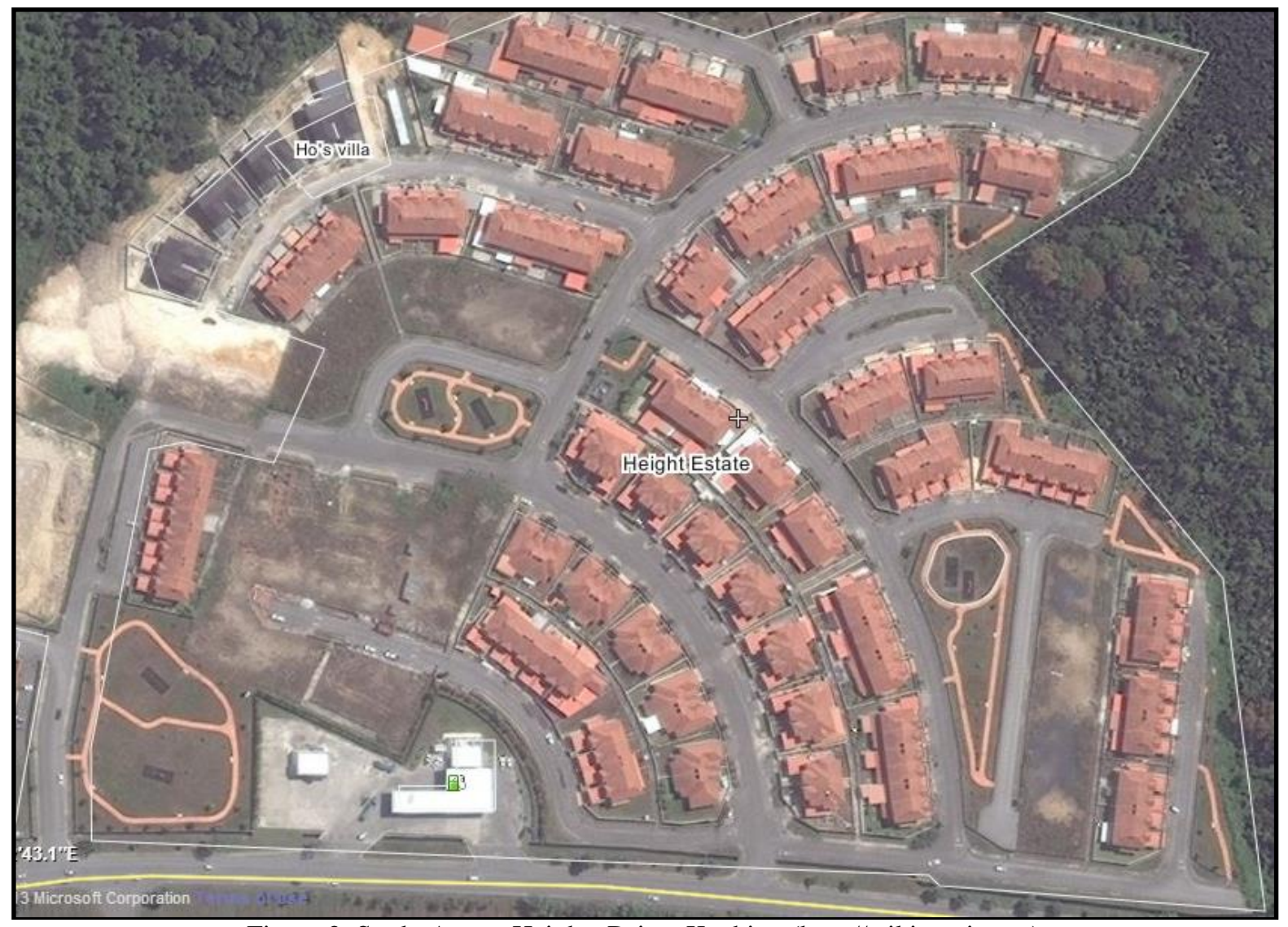

Figure 2. Study Area - Heights Drive, Kuching (http://wikimapia.org)

The driving force behind all stormwater studies and design is rainfall. In this study, 15-minute design rainfalls with 2-, 5- and 10-year average recurrence intervals (ARI) are calculated, which are 136, 150.8 and $161.2 \mathrm{~mm} /$ hour respectively. In order to distinguish the effectiveness of the studied measure, residential houses are excluded from the modelling efforts. Road catchments are relatively small thus 15-minute rainfall is adopted. MSMA has suggested 10-year ARI as the basis of design for residential areas. The rainfall-runoff processes are simulated using Storm Water Management Model (SWMM). The hydraulic engine of SWMM has been proven and tested more than 40 years and is reported the most widely applied stormwater model in US [10]-[11].

The existing conditions are that rainwater is intercepted by tar road surfaces to produce runoff, in which the running waters flow to the drain beside the road (Figure 3). Figures 4 and 5 show the proposed WSUD concepts of porous pavement, underground storage and outlet. It should be noted, the detention follows the size of the road as depicted in Figure 4. Surface area of detention system therefore is equivalent to those of road. As shown in Figure 5, the subbase is clayey as the common soil found on the site. It is perceived able to support the load above it (detained rainwater, porous pavement, vehicles) compared to other soils. Stormwater is able to infiltrate to the ground through clayey soil, although it is very slow [12]. 


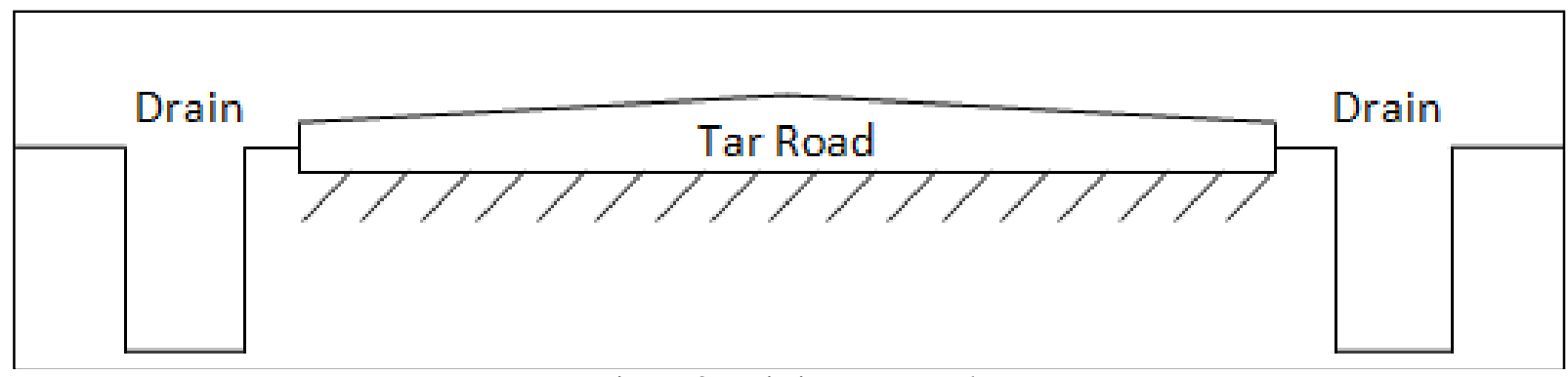

Figure 3. Existing Tar Road

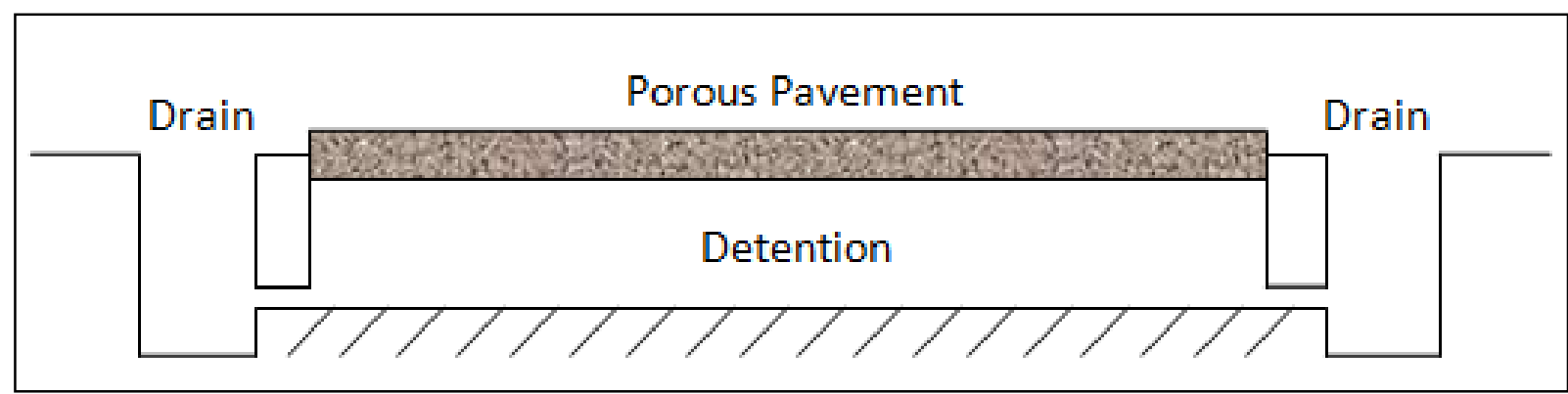

Figure 4. Proposed Concept

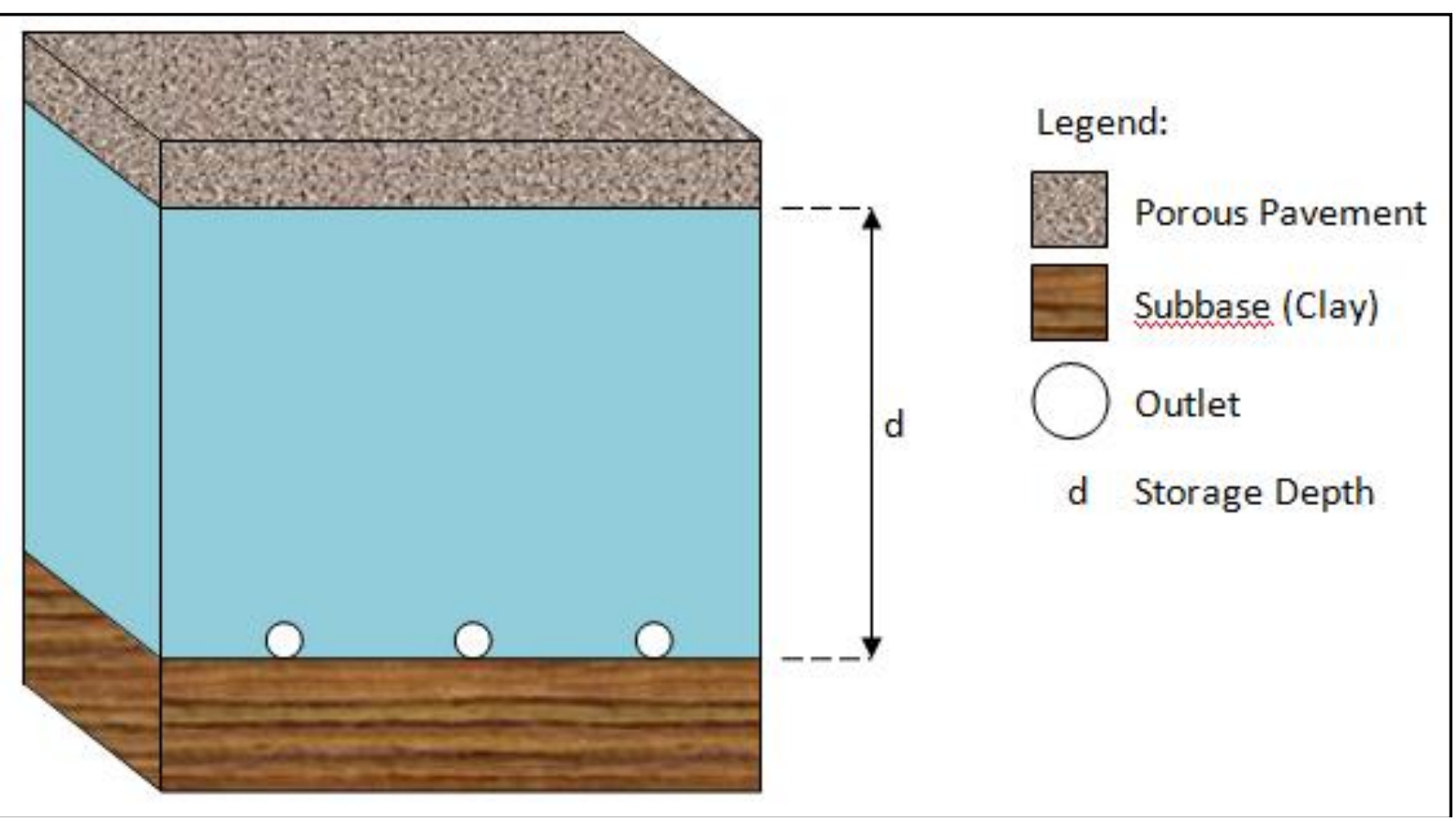

Figure 5. Storage Underneath Porous Pavement

\subsection{RESULTS AND DISCUSSION}

Nine roads in Heights Drive (Stutong), Kuching with a total surface area of 12,660 $\mathrm{m}^{2}$ are selected for this study as shown in Figure 6. A total of six scenarios are simulated. Scenarios 1, 3 and 5 are the existing conditions (Figure 7), where a two-lane road is modelled in such a way half of the runoff drains to one side drain and another half to the opposite side drain; with the exception of some roads/stretches that only has one side drain.

Scenarios 2, 4 and 6 are simulated with the addition of porous pavement, twenty-six storages and outlets (Figure 8). Outlet is basically a boundary condition that a rating curve is defined for outflow of detention system, in which $\mathrm{Q}=\mathrm{y}^{0.5}$ where $\mathrm{y}=\mathrm{depth} / \mathrm{head}$. It means the outflow depends on the depth of detained rainwater in the storage, so higher depth gives higher discharge. 
Referring to Figure 8, take the example of Road 1 that has two side trains, two underground storages are allocated for half of runoff each. Road 3 has only one side drain as no drain is available at the perimeter of the small garden and therefore a single underground storage is provided. However, for roads with longer span, like Road 9, six storages are provided with three at each side.

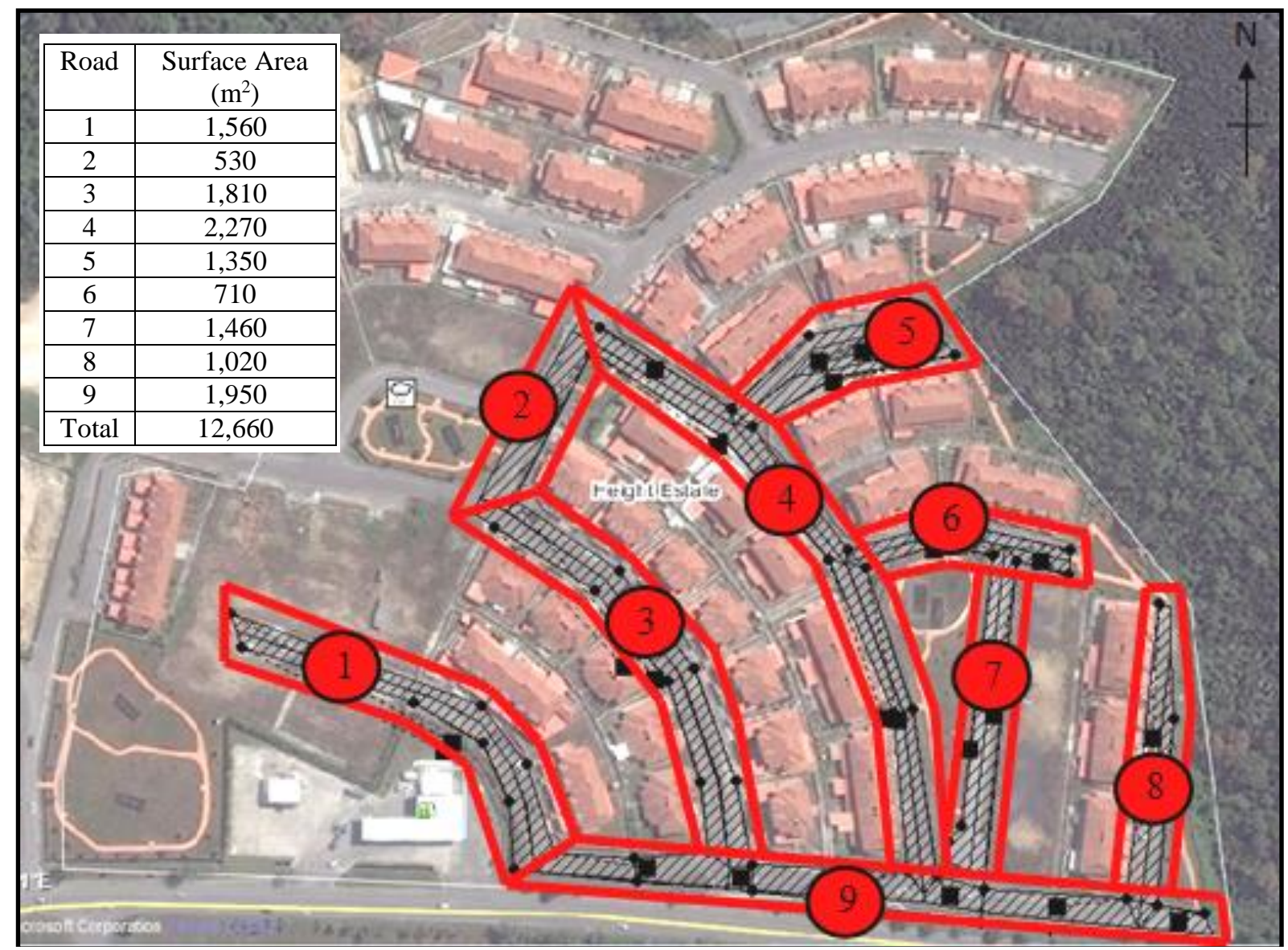

Figure 6. Selected Roads for Modelling

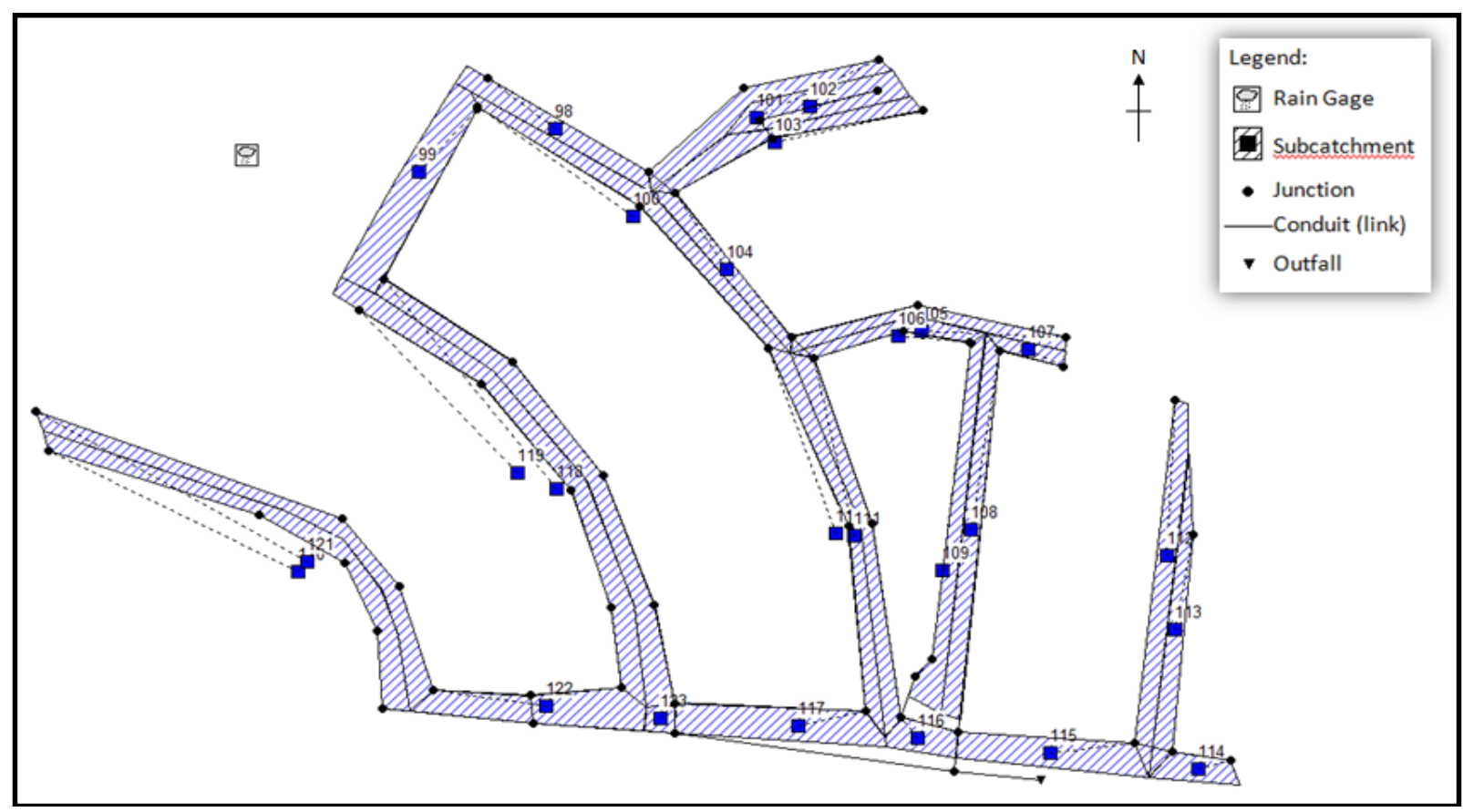

Figure 7. Scenarios 1, 3 and 5 - with Existing Tar Road 


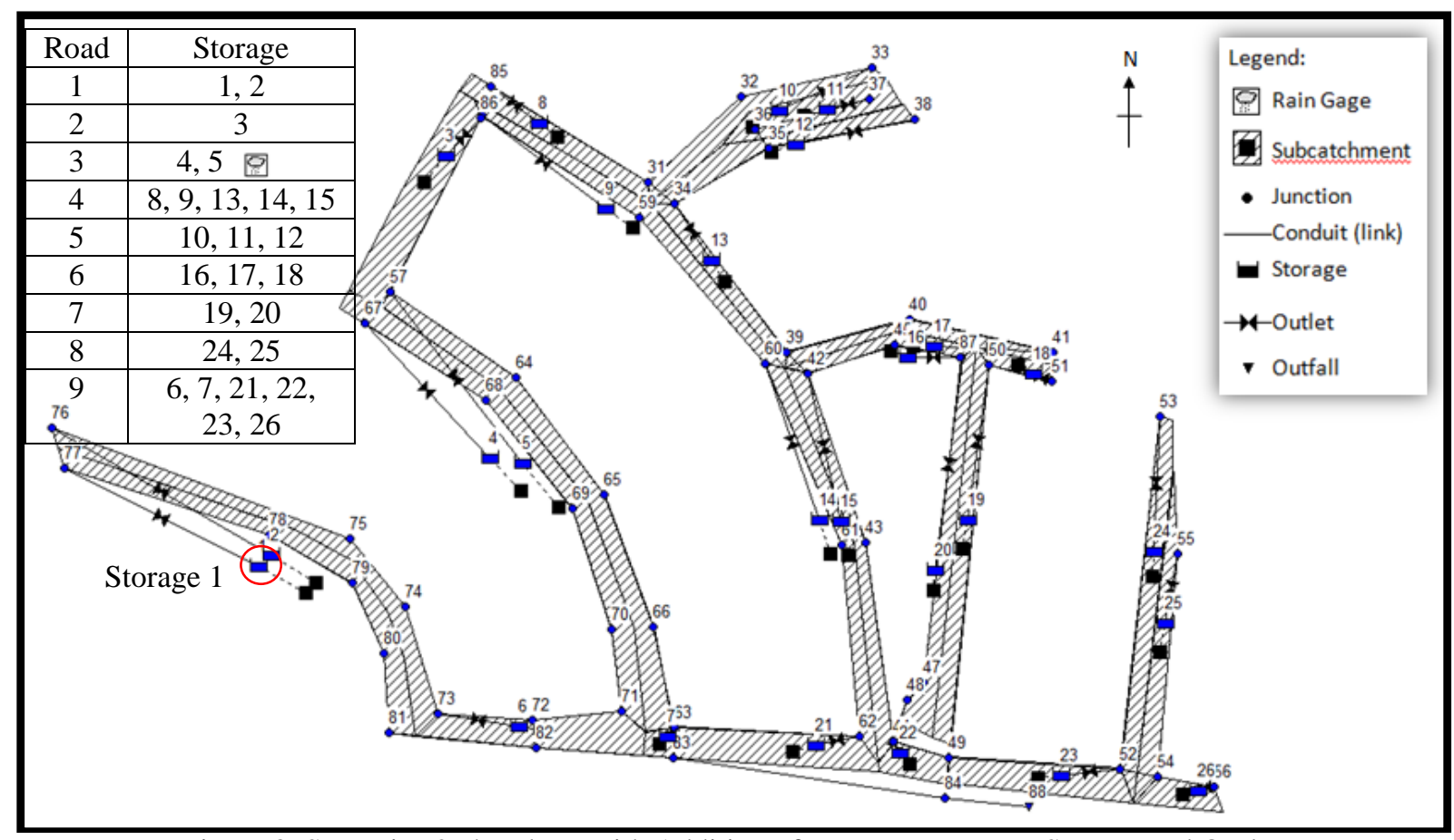

Figure 8. Scenarios 2, 4 and 6 - with Addition of Porous Pavement, Storage and Outlet

The results of all six scenarios are divided into 3 categories, namely Scenarios 1 and 2 with 2-year ARI, Scenarios 3 and 4 with 5-year ARI, and Scenarios 5 and 6 with 10-year ARI.

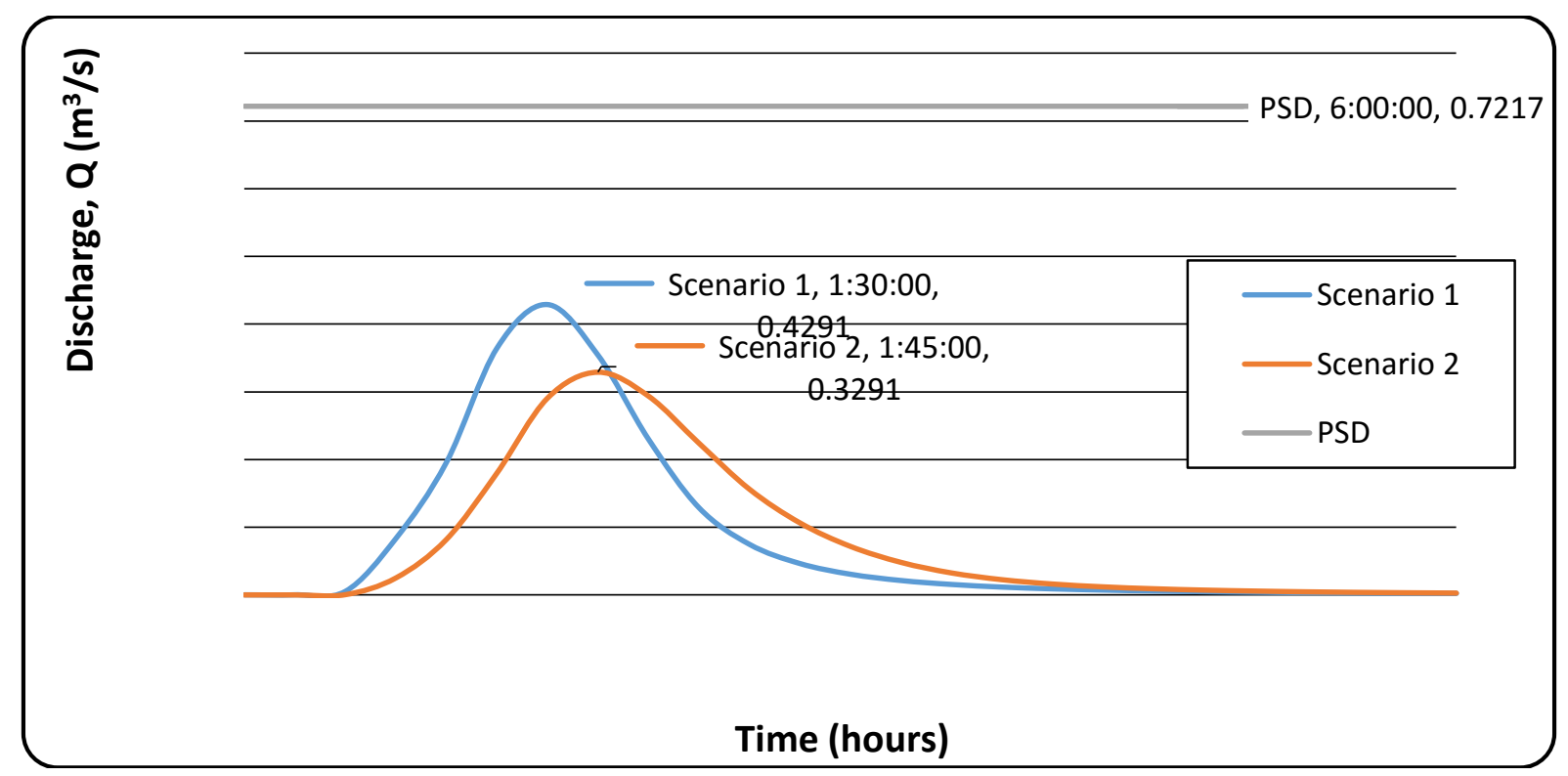

Figure 9. Discharges at Outfall for 2-year ARI Event 


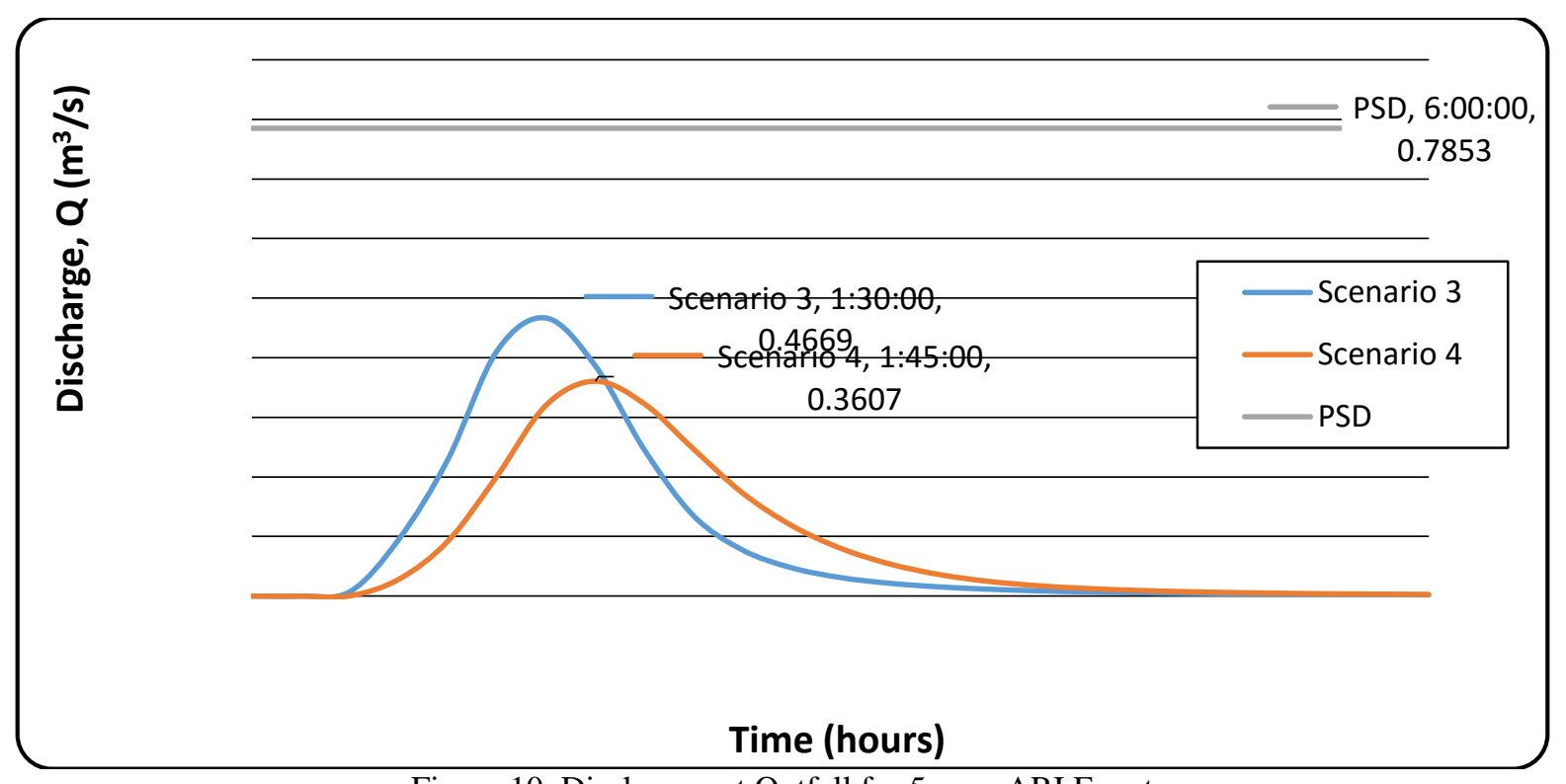

Figure 10. Discharges at Outfall for 5-year ARI Event

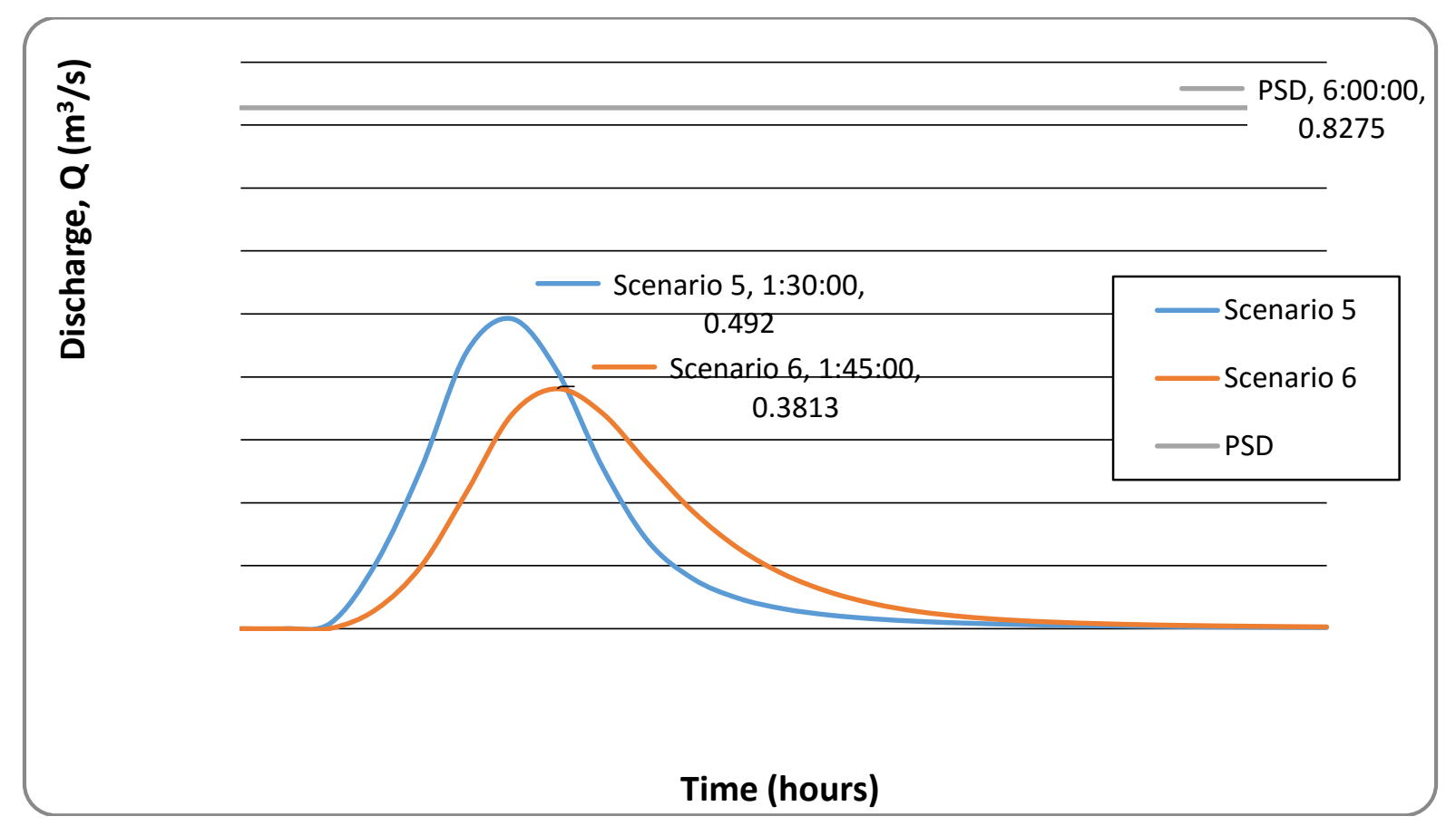

Figure 11. Discharges at Outfall for 10-year ARI Event 


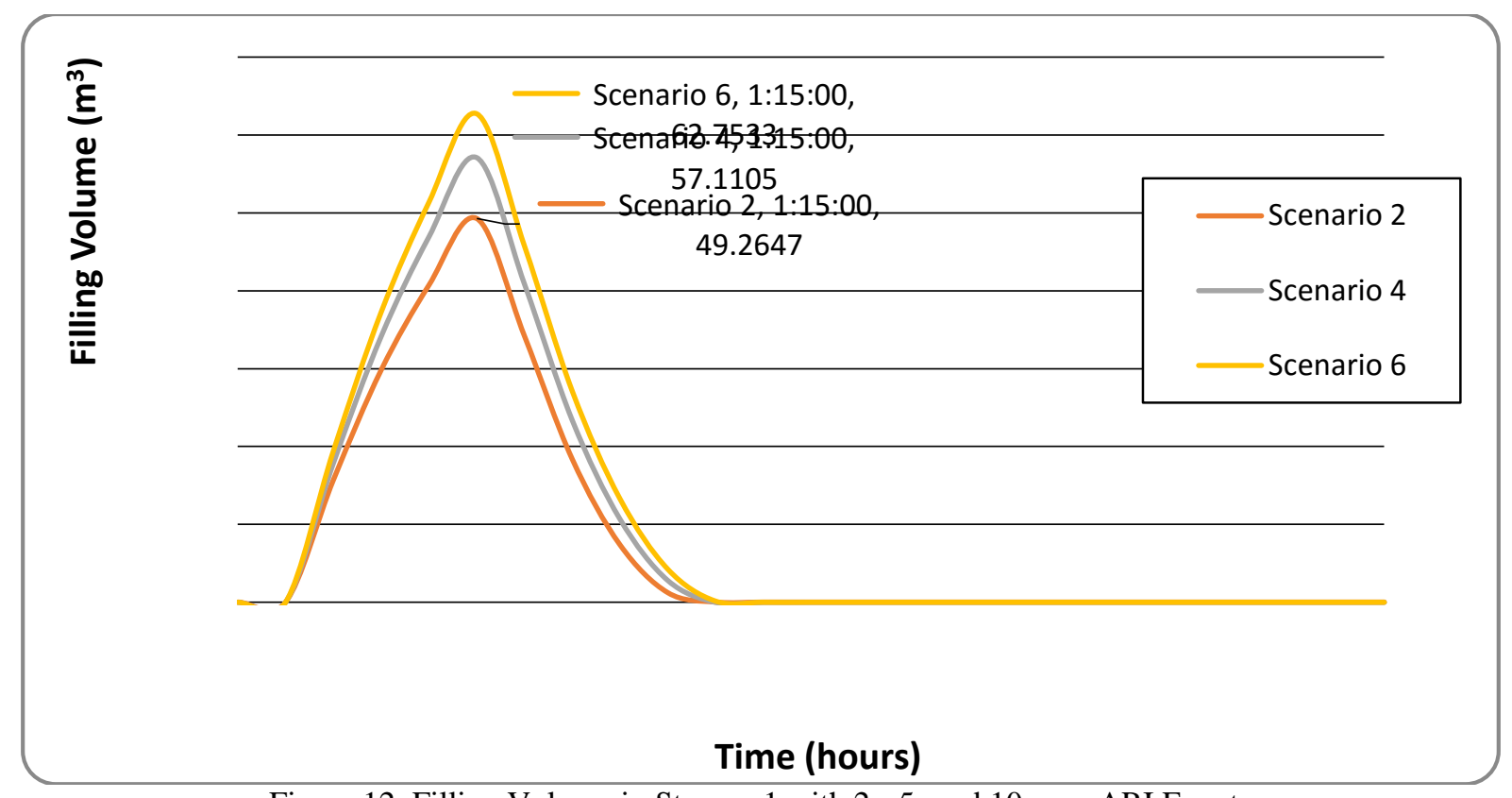

Figure 12. Filling Volume in Storage 1 with 2-, 5- and 10-year ARI Events

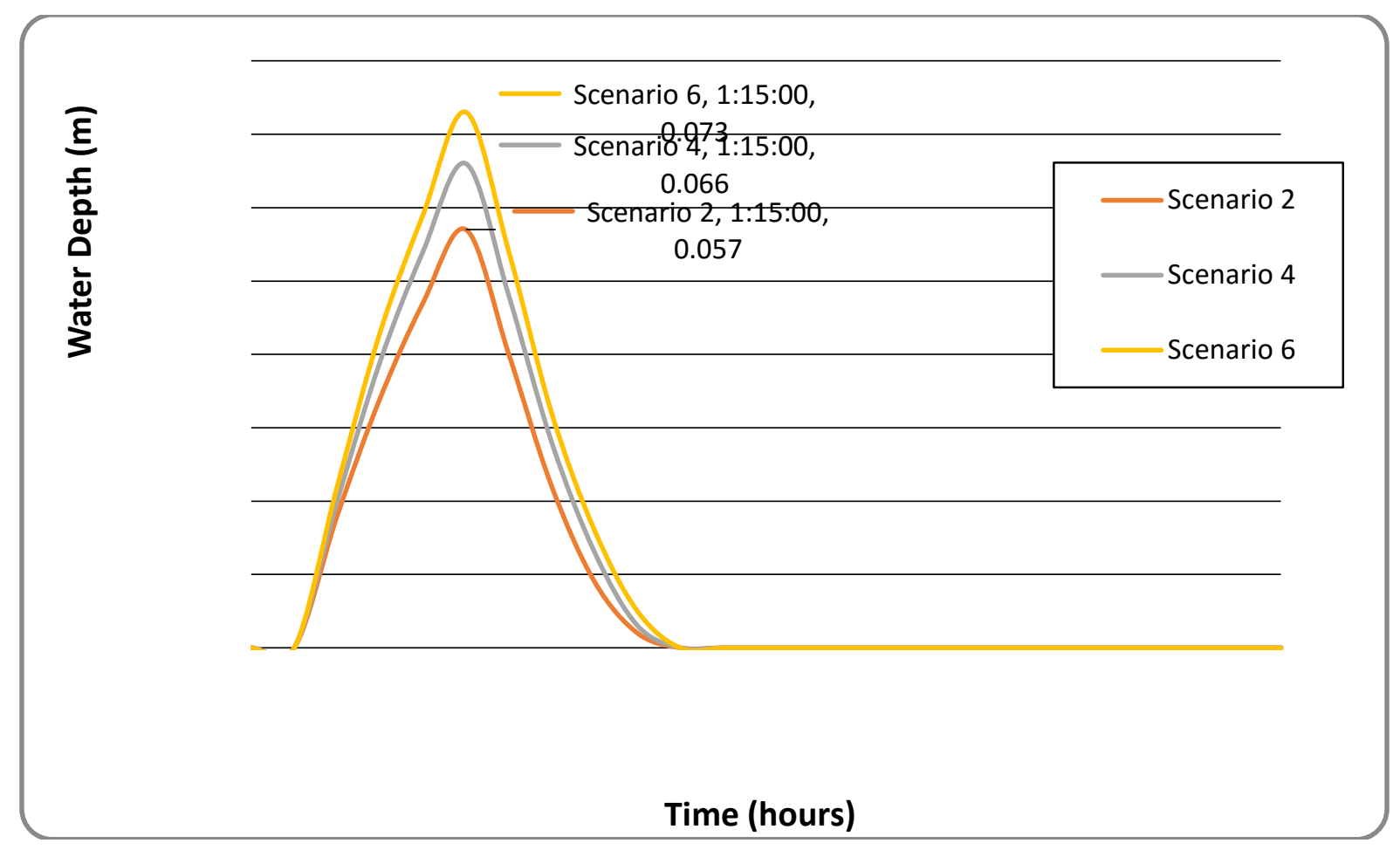

Figure 13. Water Depth in Storage 1 with 2-, 5- and 10-year ARI Events

The discharges at outfall for 2-, 5- and 10-year ARI events show similar trends but higher values of peak discharges with greater ARI. From Figures 9, 10 and 11, scenarios with storage attenuate the peak discharge towards right and with lower peak discharges. All scenarios achieve the Permissible Site Discharge (PSD) that is calculated solely based on the delineated road catchments. Peak discharges for Scenarios 1, 3 and 5 are 40.54\% lower than PSD. Addition of porous pavement and detention system decreases the peak discharges, which is $54.4 \%$ (Scenario 2), $54.07 \%$ (Scenario 4) and $53.92 \%$ (Scenario 6) lower than PSD.

Even though the model consists of twenty-six storages, only Storage 1 is presented here since the trends of the results are repetitive in all storages. Storage 1 is emptied at 2.5 hours as shown in Figures 12 and 13. Higher ARI results in higher peak volumes and water depths, assuming that rainwater percolates in downward movement in steady state. The maximum water depth is $73 \mathrm{~mm}$ and it is not affected by 
storage depth as the surface area is much greater than the depth. Thus, the depth of the storage is set to $100 \mathrm{~mm}$, allowing extra spaces of $37 \%$ to cater for weather variability. Detained rainwater in each storage has $2 \%$ loses as infiltration. Therefore, $2 \%$ of the overall stormwater is infiltrated to the ground.

\subsection{CONCLUSION}

Incorporating WSUD approach in urban development reduces the need for expensive infrastructure, lessen the impact of floods, reduce pollutants, and create environmental diversity and amenities for leisure and recreation. In this study, nine roads with low traffic volume in Heights Drive (Stutong), Kuching are selected and a stormwater conveyance model incorporating porous pavement and detention system is developed using SWMM 5.0. The proposed WSUD indicates more efficient land use by eliminating the need for detention pond.

This study has successfully modelled the porous pavement with detention system and demonstrated its effectiveness. Addition of underground storage with total surface area of $12,660 \mathrm{~m}^{2}$ and $100 \mathrm{~mm}$ depth has decreased $23 \%$ of peak discharge from the study area, in which $2 \%$ of the stormwater is infiltrated to the ground for groundwater recharge.

\section{ACKNOWLEDGMENT}

The authors express gratitude to opportunity, research, financial supports rendered by Universiti Malaysia Sarawak through Small Grant Scheme F02(S147)/1127/2014(12).

\section{REFERENCES}

[1] T. H. F. Wong, 2006. Water Sensitive Urban Design - the Journey Thus Far. Australian Journal of Water Resources. 10(3): $213-222$.

[2] A. J. Wyatt, 2011. Water Sensitive Urban Design. Proceedings of the Twenty-First Tennessee Water Resources Symposium. Tennessee, Montgomery Bell State Park Burns, US.

[3] S. H. Lai, and D. Y. S. Mah, 2012. Field Investigation of a Dry Detention Pond with Underground Detention Storage. Hydrological Sciences Journal. 57(6): 1249-1255.

[4] D. Y. S. Mah, A. H. bin Mohamad Salehe, and F. J. Putuhena, 2014. Water Sensitive Urban Design in Existing Urban Settings: Case Study of Dry Detention Pond in Kuching City. In InCIEC 2013 (pp. 315-322). Springer Singapore. doi:10.1007/978-981-4585-02-6 27

[5] E. Thelen, and L. C. Howe (1978). Porous Pavement. Philadelphia, Pennsylvania: Franklin Institute Press.

[6] C. J. Pratt, J. D. G. Mantle, and P. A. Schofield, 1989. Urban Stormwater Reduction and Quality Improvement through the Use of Permeable Pavements. Water Science and Technology. 21(8-9): 769-778.

[7] E. V. Diniz, 1980. Porous Pavement Phase 1-Design and Operational Criteria. Cincinnati, U.S.: Municipal Environmental Research Laboratory.

[8] W. Schlüter, and C. Jefferies, 2004. Modelling the Outflow from a Porous Pavement. Urban Water. 4(3): 245-253.

[9] M. Legret, V. Demare, and C. LeMarc, 1996. Effects of a Porous Pavement with Reservoir Structure on the Quality of Runoff Water and Soil. Science of Total Environment. 190: 335-340.

[10] V. A. Tsihrintzis, and R. Hamid, 1998. Runoff Quality Prediction from Small Urban Catchments using SWMM. Hydrological Processes. 12(2): 311329.

[11] T. Lockie, 2009. Catchment Modelling using SWMM. In Modelling Stream at the $49^{\text {th }}$ Water New Zealand Annual Conference and Expo.

[12] A. Dreelin, L. Fowler, and R. Carroll, 2006. A Test for Porous Pavement Effectiveness on Clay Soil during Natural Storm Events. Water Research. 40(4): 799-805 